\section{Streptococcus bovis endocarditis and colonic carcinoma: a neglected association}

In 1977 Klein et al drew attention to an association between Streptococcus bovis endocarditis and carcinoma of the colon ${ }^{1}$; later this observation received support from other published case reports. ${ }^{23} \mathrm{We}$ describe a further patient in whom the finding of Str bovis endocarditis stimulated investigation which resulted in the diagnosis and treatment of carcinoma of the sigmoid colon. Few earlier reports give details of the Str bovis biotype implicated, which in this particular case differed from the biotype of the organism more commonly associated with endocarditis. ${ }^{4}$

\section{Case report}

A 58 year old woman was admitted to the intensive care unit of this hospital in July 1982 with suspected acute toxic confusion. She was feverish (temperature $38^{\circ} \mathrm{C}$ ) and delirious; her haemoglobin concentration had fallen from 12.0 $\mathrm{g} / \mathrm{dl}$ earlier that year to $9.7 \mathrm{~g} / \mathrm{dl}$ on admission. She was clearly in cardiac failure secondary to valvular heart disease with established atrial fibrillation: her ventricular rate was $84 / \mathrm{min}$ and blood pressure $130 / 65 \mathrm{~mm} \mathrm{Hg}$. On auscultation a grade $3 / 4$ systolic murmur was maximal at the base but widely audible over the precordium and there was a grade $2 / 3$ early diastolic murmur at the left sternal edge. No abnormalities were noted on abdominal examination.

The patient was known to have had rheumatic heart disease, having suffered four discrete attacks of rheumatic fever in youth, which had resulted in rheumatic endocarditis. Both aortic and mitral valves were severely affected and had been replaced by homograft valves in 1967 and 1979 respectively. Later a history of intermittent mild diarrhoea lasting a few days at a time and without obvious rectal blood loss came to light. This symptom, which dated from June 1981, had led in August 1981 to sigmoidoscopic and barium enema examinations, neither of which had shown anything abnormal. Immediately before the present admission, however, persistent diarrhoea had again been troublesome.

In this setting of apparent acute toxic confusion associated with changing murmurs (the diastolic murmur had not been heard before) several blood cultures were taken immediately, all of which rapidly grew Str bovis biotype II, as identified by "API 20 strep." Intravenous ampicillin (later replaced by intravenous benzylpenicillin) and gentamicin led to resolution of confusion as her temperature fell to normal over a few days. While the findings on auscultation were unchanged, her exercise tolerance rapidly returned to a preadmission level with continued maintenance digoxin, diuretic, and anticoagulant treatment.

Although no intrinsic lesion was palpable on rectal examination, the impression of a high pelvic mass and the identification of this particular $S t$ bovis as responsible for her endocarditis led to an intensive search for further evidence of colonic carcinoma. Sigmoidoscopy on two separate occasionsto $15 \mathrm{~cm}$ using a rigid instrument, and to $30 \mathrm{~cm}$ with a flexible instrument used under general anaesthesia-showed only traces of intraluminal blood, which presumably derived from a more proximal bowel condition. A further barium enema examination failed to detect such a lesion but was technically unsatisfactory, and when repeated an irregular narrowing of the proximal sigmoid colon was seen.

At laparotomy under continued antibiotic cover with temporary anticoagulant reversal a tumour $6 \times 3 \times 3 \mathrm{~cm}$ situated at the apex of the sigmoid colon was excised by sigmoid colectomy. Histologically this was a moderately differentiated adenocarcinoma which had infiltrated at least one lymph node beside the inferior mesenteric artery. There was, however, no other evidence of metastatic spread. Postoperative recovery was uneventful and bowel symptoms did not recur. Though she continued to have an aortic diastolic murmur, her overall cardiorespiratory state remained satisfactory.

\section{Comment}

The relevance of the association reported by Klein et al between Str bovis endocarditis and colonic adenocarcinoma appeared enhanced by their finding of an increased prevalence of Str bovis isolation from patients with colonic carcinoma when compared with controls. ${ }^{1}$ Later other workers ${ }^{5}$ advocated full evaluation of the gastrointestinal tract in the investigation of patients with Str bovis bacteraemia (with or without endocarditis) on the basis of a high frequency of isolation of this streptococcus type from patients with varied gastrointestinal disease.

An earlier review of streptococcal disease showed that Str bovis was responsible for $55(17.4 \%)$ of 317 cases of streptococcal endocardi- tis. ${ }^{4}$ The vast majority of the organisms, however, belonged to Str bovis biotype I (dextran producing, mannitol fermenting) rather than Str bovis biotype II (non-dextran producing, non-mannitol fermenting), the organism type responsible for endocarditis in our patient. Indeed, of the 317 cases of endocarditis reviewed by Parker and Ball, only seven were caused by Str bovis biotype II.4 The relevance of the fact that our patient's isolate belonged to the biotype less commonly associated with endocarditis is not clear, as few other reports give details of the Str bovis biotype associated with gastrointestinal lesions. Conceivably attention to more detailed identification of the organism in such cases may further increase our understanding of the association between Str bovis endocarditis and colonic carcinoma.

${ }^{1}$ Klein RS, Rose A, Recco MD, et al. Association of Streptococcus bovis with carcinoma of colon. N Engl f Med 1977;297:800-2.

2 Noble CJ, Ohley AMC, Falk RH, Richardson PJ. Streptococcus bovis endocarditis and colonic cancer. Lancet 1978; ; :766.

${ }^{3}$ Steinberg D, Naggar CZ. Streptococcus bovis endocarditis with carcinoma of colon. N Engl f Med 1977;297:1354-5.

4 Parker MT, Ball LC. Streptococci and aerococci associated with systemic infection in man. $\mathcal{F}$ Med Microbiol 1976;9:275-302.

${ }^{5}$ Murray HW, Roberts RB. Streptococcus bovis bacteremia and underlying gastrointestinal disease. Arch Intern Med 1978;138:1097-9.

(Accepted 29 March 1983)

Dumfries and Galloway Royal Infirmary, Dumfries DG1 4AP

$\mathrm{K}$ HOSSENBUX, MRCP, registrar in medicine

B A S DALE, DIPBACT, MRCPATH, consultant bacteriologist

A D F WALLS, MB, FRCs, consultant surgeon

J R LAWRENCE, MD, MRCP, consultant physician

Correspondence to: Dr J R Lawrence.

\section{Cerebrotendinous xanthomatosis: biochemical response to inhibition of cholesterol synthesis}

Cerebrotendinous xanthomatosis is a rare disabling genetic disorder in which cholestanol accumulates in the nervous system and other tissues. We describe a patient severely affected by the disease in whom the raised plasma cholestanol concentration was profoundly reduced by mevinolin, a drug that inhibits cholesterol biosynthesis.

\section{Case report}

A 27 year old man presented with increasing unsteadiness of gait and swelling of his Achilles tendons. Five years before bilateral cataracts had been removed with improvement in vision. There were no similar illnesses in his family, but he was born to consanguineous parents. A paternal aunt had died of coronary heart disease at age 40 . Although his father indicated that there had been slight intellectual slowing, he was able to work as a school clerk.

The patient was slightly dysarthric. Psychometric testing in English and Arabic disclosed intellect and memory in the dull normal range (full scale IQ 80-85). His severely ataxic gait was disproportionate to the minimal pyramidal weakness and mild spasticity. He had bilateral ankle clonus, extensor plantar responses, and brisk limb reflexes. Vibration sense was reduced at his ankles. There were large xanthomas in both Achilles tendons and in the plantar tendons. The liver was enlarged. Computed tomography showed slight generalised cerebral atrophy. The electroencephalogram was severely and diffusely abnormal with an excess of medium to high voltage mixed slow activity. Electromyography showed delayed motor conduction, suggesting peripheral nerve disease.

The diagnosis of cerebrotendinous xanthomatosis was confirmed by measurement of the plasma cholestanol concentration by gas chromatography; values were $16 \cdot 8$ and $13.3 \mathrm{mg} / 1$ (normal range $2 \cdot 0-6 \cdot 0 \mathrm{mg} / 1^{1}$ ). Cholestanol constituted $3.0 \%$ of sterols extracted from an Achilles tendon biopsy specimen. Cholesterol concentrations were 6.6 and $7 \cdot 1 \mathrm{mmol} / 1$ (255 and $274 \mathrm{mg} / 100 \mathrm{ml}$ ), exceeding the $90 \mathrm{th}$ percentile, due to a small increase of low density lipoprotein. Serum alkaline phosphatase activity was $160 \mathrm{KAU} / 1$ (upper limit 130), attributable to an increase in bone isoenzyme. The resting electrocardiogram was normal. 


\section{Comment}

Cerebrotendinous xanthomatosis is an autosomal recessive lipid storage disease characterised by accumulation of cholestanol and cholesterol in the brain and other tissues. ${ }^{1}$ Common manifestations are tendon xanthomas, cataracts, progressive dementia, ataxia, spinal cord signs, and coronary heart disease. ${ }^{12}$ No effective treatment has been documented. ${ }^{1}$

Cholestanol is a product of the metabolism of cholesterol in mammalian tissues. ${ }^{3}$ The first step in normal hepatic degradation of cholesterol to bile acids is dependent on mitochondrial steroid 26-hydroxylase. Absence of this enzyme, first hypothesised by Myant ${ }^{3}$ appears to be the underlying defect ${ }^{4}{ }^{5}$ and may divert sterols from the normal pathways of bile acid synthesis. In view of the serious prognosis in cerebrotendinous xanthomatosis and in the absence of noticeable dementia in our patient treatment was instituted with low dose (6.25 mg twice daily) mevinolin, a competitive inhibitor of hydroxymethylglutaryl coenzyme $A$ reductase. There were no untoward clinical findings. Blood pressure remained unchanged. A biochemical profile of 13 tests and routine haematological studies showed no trends nor deviations from reference ranges. The figure gives the sterol and steroid hormone concentrations. Serum cholestanol
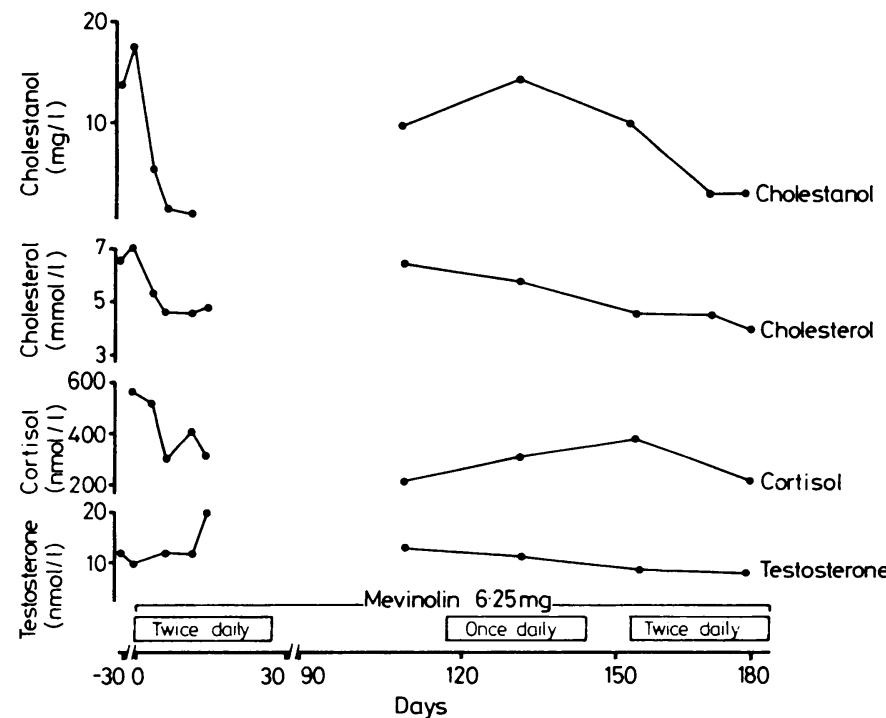

Effects of mevinolin on plasma concentrations of cholestanol, cholesterol, cortisol, and testosterone.

Conversion: SI to traditional units-Testosterone: $1 \mathrm{nmol} / 1 \approx 0.3 \mathrm{ng} / \mathrm{ml}$. Cortisol: $1 \mathrm{nmol} / 1 \approx 0.04 \mu \mathrm{g} / 100 \mathrm{ml}$. Cholesterol: $1 \mathrm{mmol} / 1 \approx 38.6 \mathrm{mg} / 100 \mathrm{ml}$.

(Successful use of chenodeoxycholic acid in cerebrotendinous xanthomatosis was reported by G Salen et al (Circulation 1982;66:II-238 (abstract)). In that study mean plasma cholestanol concentration during treatment fell to $8 \cdot 0$ $\mathrm{mg} / \mathrm{l}$ - that is, reduction was less pronounced than that achieved by mevinolin. Despite this, treatment for one year was associated with improvement in electroencephalographic abnormalities.)

values became normal within four days after beginning mevinolin and decreased further to low normal. Mean plasma cholesterol concentration decreased by $32 \%$; mean high density lipop:otein cholesterol value did not change substantially $(1.2 \mathrm{mmol} / 1(46.3 \mathrm{mg} / 100 \mathrm{ml})$ before, $1.4 \mathrm{mmol} / 1(54.1 \mathrm{mg} / 100 \mathrm{ml})$ during treatment), nor did mean plasma triglyceride values change in fasting samples $(2.3 \mathrm{mmol} / 1$ $(204 \mathrm{mg} / 100 \mathrm{ml})$ before and during treatment). Plasma cortisol and testosterone concentrations fluctuated within the normal range.

After five months it was too soon to assess the effect of treatment on the neurological disability (computed tomographic scan and electroencephalogram were unchanged), but it is of interest that inhibition of cholesterol synthesis rapidly corrected the high plasma cholestanol concentration. In the first five months of treatment the liver became smaller and the xanthomas showed signs of regression. The reduction in plasma cholestanol was striking and exceeded that in plasma cholesterol; this would be expected if, in the untreated state, tissue concentrations of cholestanol saturated a rate limiting step in its catabolism.

We thank Merck, Sharp and Dohme Ltd for generously supplying mevinolin.
' Bhattacharyya AK, Connor WE. Familial diseases with storage of sterols other than cholesterol. In: Stanbury JB, Wyngaarden JB, Fredrickson DS, eds. Metabolic basis of inherited disease. 4th ed. New York: McGrawHill, 1978:ch 31 .

2 Stahl WL, Sumi SM, Swanson PD. Subcellular distribution of cerebral cholestanol in cerebrotendinous xanthomatosis. 7 Neurochem 1971;18: 403-9.

${ }^{3}$ Myant NB. The biology of cholesterol and related sterols. London: Heinemann Medical, 1981 :ch 5, p 287 ;ch 17, p 843.

4 Oftebro H, Bjorkhem I, Skrede S, Schreiner A, Pedersen JI. Cerebrotendinous xanthomatosis. A defect in mitochondrial 26-hydroxylation required for normal biosynthesis of cholic acid. $\mathcal{f}$ Clin Invest 1980;65: 1418-30.

5 Javitt NB, Kok E, Cohen B, Burstein S. Cerebrotendinous xanthomatosis : reduced serum 26 -hydroxycholesterol. $\mathcal{F}$ Lipid Res $1982 ; 23: 627-30$.

(Accepted 12 April 1983)

Department of Chemical Pathology and Metabolic Disorders, St Thomas's Hospital Medical School, London SE1 7EH

B LEWIS, FRCP, FRCPATH, professor

W D MITCHELL, FRSC, MRCPATH, top grade biochemist

C B MARENAH, PHD, MRCP, lecturer

C CORTESE, MD, lecturer

Maudsley and King's College Hospitals, London

E H REYNOLDS, MD, FRCP, consultant neurologist

University Department of Neurology, Faculty of Medicine, Kuwait R SHAKIR, MRCP, consultant neurologist

Correspondence to: Professor B Lewis.

\section{Anaphylactoid purpura presenting as a medical and surgical emergency}

Anaphylactoid purpura, a disease primarily of young children, is a well recognised though infrequent syndrome in the adult. ${ }^{1}$ We report a case mimicking gastrointestinal obstruction and pulmonary embolus which was associated with thrombocytosis.

\section{Case report}

A 59 year old man presented with pronounced abdominal distension for two days. There was no abdominal pain and he had not passed faeces or flatus for over 24 hours. In addition, four hours previously he had suddenly developed pleuritic type chest pain at the base of his right lung posteriorly with an episode of minimal haemoptysis. Three weeks before admission an uneventful left tibial osteotomy for osteoarthrosis had been performed.

On admission he was pyrexial $\left(38 \cdot 2^{\circ} \mathrm{C}\right)$, tachypnoeic, and centrally cyanosed. His pulse was regular at $100 / \mathrm{min}$ and the jugular venous pressure was raised. There was decreased air entry at both lung bases with coarse crepitations. The abdomen was distended with minimal generalised tenderness and high pitched obstructive bowel sounds.

Initial investigations showed: haemoglobin concentration $16.5 \mathrm{~g} / \mathrm{dl}$; white cell count $26 \cdot 1 \times 10^{9} / 1\left(26100 / \mathrm{mm}^{3}\right)$; erythrocyte sedimentation rate $114 \mathrm{~mm}$ in first hour; platelet count $700 \times 10^{9} / 1\left(700000 / \mathrm{mm}^{3}\right)$; blood urea and serum electrolyte concentrations normal; arterial blood gases, $\mathrm{Po}_{2} 6.4 \mathrm{kPa}(48 \mathrm{~mm} \mathrm{Hg}), \mathrm{PcO}_{2} 5.1 \mathrm{kPa}(38.3 \mathrm{~mm} \mathrm{Hg})$, hydrogen ion $36 \mathrm{mmol} / \mathrm{l}$. Chest $x$ ray films showed bilateral basal consolidation with atelectasis in the right mid-zone suggesting infarction. Erect and supine abdominal $x$ ray films confirmed large bowel gaseous distension with several fluid levels.

Pulmonary embolus was suspected and he was treated with intravenous heparin and high flow oxygen. The asymptomatic abdominal signs persisted, developing into frank gastrointestinal obstruction five days later with constipation, copious vomiting, severe central colicky abdominal pain, and generalised guarding. He developed pain in both wrists and a maculopapular rash on the extensor surface of the thighs and calves, which progressed within 24 hours to palpable purpura and superficial necrotic areas of up to $1 \mathrm{~cm}^{2}$ in diameter.

The initial leucocytosis returned to normal; the thrombocytosis, however, increased to $1010 \times 10^{9} / 1\left(1010000 / \mathrm{mm}^{3}\right)$. Tests for faecal occult blood were consistently negative although microscopic haematuria and proteinuria developed. Other investigations, including screening tests for organ specific autoantibodies, antinuclear factor, and sputum pneumococcal capsular antigen, were negative. The only biochemical abnormalities were an increase in serum alanine aminotransferase and alkaline phosphatase (liver origin) reaching peaks of $108 \mathrm{IU} / 1$ (normal range $=10-40 \mathrm{IU} / \mathrm{l}$ ) and $236 \mathrm{IU} / 1$ (normal 